\title{
Desigualdades de gênero na democracia brasileira
}

\author{
Gender Inequalities in Brazilian Democracy \\ Camila Borges Machado' (iD) 0000-0002-9378-6713 \\ 'Universidade Federal de Juiz de Fora, Programa de Pós-Graduação em Psicologia, Juiz \\ de Fora, MG, Brasil. 36036-330 -ich@ufjf.edu.br
}

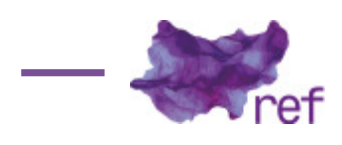

BIROLI, Flávia.

Gênero e desigualdades: limites da democracia no Brasil.

São Paulo: Boitempo, 2018.

Gênero e desigualdades: limites da democracia no Brasil, publicado pela Editora Boitempo em 2018, promove acalorados debates sobre os temas em torno do feminismo, tendo como pano de fundo o cenário político e os limites da democracia brasileira. A partir do acúmulo do debate teórico feminista sobre a política, as discussões tecidas se ancoram na vida cotidiana de uma grande parcela da população, sobretudo na das mulheres (pretas e pardas) da classe trabalhadora. Nesse sentido, a obra discute o momento presente, o que é em si uma tarefa árdua, e apoia-se em uma vasta bibliografia tanto de pesquisas recentes, como nos clássicos estudos sobre a temática de gênero, de modo a conferir ritmo e riqueza ao texto.

A autora, Flávia Biroli, possui graduação em Jornalismo pela Universidade Estadual Paulista Júlio de Mesquita Filho (UNESP), mestrado e doutorado em História pela Universidade Estadual de Campinas (UNICAMP). Atualmente, é professora associada do Instituto de Ciência Política da Universidade de Brasília (UnB), pesquisadora do CNPq e presidenta da Associação Brasileira de Ciência Política (2018-2020), atuando ativamente em diversos projetos que relacionam os estudos de gênero. Além de Gênero e desigualdades: limites da democracia no Brasil, a autora tem como principais obras: Autonomia e desigualdades de gênero: contribuições do feminismo para a crítica democrática (2013), Feminismo e democracia (2014) e Família: novos conceitos (2014).

Ao assumir o seu interesse em colaborar com a compreensão das desigualdades de gênero e apontar caminhos para a superação destas relações desiguais, Biroli (2018), em Gênero e desigualdades: limites da democracia no Brasil, dialoga com cinco temáticas do feminismo que correspondem aos cinco capítulos que compõem o livro, ademais da introdução: "1. Divisão sexual do trabalho"; "2. Cuidado e responsabilidade"; "3. Família e maternidade"; "4. Aborto, sexualidade e autonomia"; "5. Feminismos e atuação política". Evidentemente, os cinco eixos de análise não esgotam o debate levantado pela autora, mas permitem compreender questões identificadas como incontornáveis para o caminho de superação dos padrões desiguais, injustos e violentos de gênero.

O debate sobre a divisão sexual do trabalho, tema do primeiro capítulo, inicia o percurso do livro. Com o propósito de levar a/o leitora/o a compreender os princípios da divisão sexual do trabalho, a autora ressalta que discutir sobre a divisão sexual do trabalho é debater sobre o que vem sendo definido, historicamente, como papel e função social da mulher, o que produz efeitos 
diretos na posição desigual entre homens e mulheres em nossa sociedade, ao passo que se constitui sob diferentes formas para o conjunto amplo de mulheres, imbricando disparidades através das relações de classe, de raça e de sexualidade. Trata-se, portanto, de um debate sensível, pois confere a todas as mulheres uma função social semelhante, bem como distingue as diferentes marcas e opressões que o sistema patriarcal, capitalista, sexista e racista imprime sobre todas nós, mulheres.

No capítulo seguinte, intitulado "Cuidado e responsabilidades", Biroli problematiza as dimensões ideológicas e socioeconômicas da atividade de cuidado atribuída às mulheres. Desde a mais tenra idade, as atividades de reprodução social, executadas pelas mulheres, são socialmente exigidas e naturalizadas. O tempo, saberes e a capacidade de trabalho feminino são perversamente condicionados ao usufruto gratuito e explorado por parte do Estado. A autora ressalta que uma das facetas mais cruéis de tal problemática é a responsabilidade atribuída às mulheres em educar e proteger suas filhas e seus filhos, em ambientes nos quais o Estado se omite na implementação de políticas sociais básicas para uma vida digna. Logo, a tendência do Estado em reduzir gastos destinados a investimentos sociais, sobrecarrega ainda mais a figura da mulher da classe trabalhadora, sobretudo as não brancas.

A partir dos debates sobre trabalho e cuidado, desenvolvidos nos dois primeiros capítulos, a autora segue com a temática da família, objeto de estudo do terceiro capítulo intitulado "Família e maternidade". Biroli é contundente ao afirmar que a concepção de família é uma construção histórica, e não um fenômeno natural da espécie humana, revelando um debate central, especialmente na atual conjuntura no país, marcada pelo acirramento do discurso conservador a respeito da moral e dos bons costumes, veiculado em defesa da família tradicional brasileira. Nesse sentido, podemos observar tanto no cenário brasileiro, como em outras partes do mundo, movimentos conservadores protagonizados - sobretudo, por grupos religiosos -, que mobilizam recursos econômicos com o propósito de fazer valer suas visões de mundo. A autora aponta alguns marcos dessa investida conservadora, como é o caso do aparecimento da noção de ideologia de gênero em documentos do Conselho Pontifício para a Família, da lgreja Católica, e nos discursos políticos que ganharam evidência nas campanhas eleitorais, envolvendo, assim, "ações que comprometem os esforços que vêm sendo enviados há décadas para que os valores presentes na educação sejam condizentes com uma sociedade efetivamente plural" (Flávia BIROLLI, 2018, p. 130). Em nome de uma suposta defesa da família, os conservadores atuam na defesa da permanência de determinados padrões sociais, os quais valorizam a atuação das mulheres no papel social de mãe, aprofundando o controle e a regulação sobre os corpos femininos e limitando suas consciências e subjetividades em função de uma maternidade serviçal.

A análise sobre a família segue relevante no quarto capítulo - "Aborto, sexualidade e autonomia" -, no qual a autora tece importantes críticas aos limites da democracia brasileira e situa o debate teórico sobre o aborto a partir das contribuições do movimento feminista. A temática do aborto está na mira de diversos grupos conservadores que têm mobilizado recursos em direção à restrição de direitos das mulheres e pessoas LGBT, movimentando uma intensa correlação de forças e disputas políticas da atuação de movimentos feministas e LGBT no âmbito estatal, assim como as reações conservadoras autointituladas de movimento Pró-Vida, em que católicos e pentecostais defendem a abstinência sexual para lidar com a gravidez indesejada e as infecções sexualmente transmissíveis, em vez de ampliar o debate sobre gênero, educação sexual e prevenção. Assim, a falácia da ideologia de gênero "tem servido para caricaturar os avanços e justificar a recusa de políticas para a igualdade de gênero e para a superação de preconceitos e violências (BIROLI, 2018, p. 163). Com isso, Biroli é cuidadosa ao tentar descrever uma série de interesses políticos que estão por trás dessa temática, apontando um caminho possível para compreender tais disputas que, conjugadas, refletiram no golpe de 2016.

Em "Feminismos e atuação política", Biroli aponta os obstáculos à participação política das mulheres e articula movimentos sociais importantes que marcam a história do Brasil. O espaço político é caracterizado, sobretudo, como masculino, heteronormativo e branco. Contudo, o movimento de mulheres e demais grupos subalternizados têm tensionado "as matrizes de dominação que são ao mesmo tempo patriarcais, racistas e colonialistas" (BIROLI, 2018, p. 172-173). Nesse aspecto, a autora aponta que as ações organizadas pelo movimento feminista têm seguido caminhos alternativos, fortalecendo suas reivindicações através de sindicatos, marchas, protestos e greves, bem como atuando em diversas frentes, entre as quais se destacam o combate à violência contra as mulheres, assédio sexual, a oferta de creches, a defesa dos direitos reprodutivos e o direito ao aborto. Ao passo que persiste o interesse material e concreto de alguns grupos em barrar as pautas feministas, consistindo em um obstáculo central para a democracia brasileira, ao traçar um paralelo entre as pautas feministas e os interesses dominantes, o livro encerra a discussão apontando os desafios da agenda e luta feminista. Todavia, a autora ressalta que a conquista de direitos de gênero não se faz, necessariamente, na contramão do pensamento dominante e nem através da representação despolitizada de parlamentares do sexo feminino, uma vez que pode 
haver avanços nos direitos das mulheres, enquanto as taxas de exploração do trabalho e a concentração de riqueza se ampliam e aprofundam os efeitos na desigualdade de raça, gênero e classe.

Mais do que postular ou comprovar teorias, Gênero e desigualdades: limites da democracia no Brasil revela um mo(vi)mento político perverso que implica uma série de desigualdades na participação política das mulheres na sociedade. Entre as discussões sobre o espaço público e o privado, costura-se um importante trabalho para pesquisadoras/es, profissionais e estudantes sobre a temática das relações de gênero. Cabe ressaltar que o livro é escrito, assim como a presente resenha, em um momento de ataque as ciências, universidade e educação pública, no qual impera a lógica da "austeridade", omitindo a face pública do Estado e ampliando relações de violência, opressão e precarização.

\section{Referência}

BIROLI, Flávia. Gênero e desigualdades: limites da democracia no Brasil. São Paulo: Editora Boitempo, 2018.

Camila Borges Machado (camilabm.01@gmail.com) é mestra e doutoranda do Programa de Pós-Graduação em Psicologia da Universidade Federal de Juiz de Fora (UFJF) na linha Processos Psicossociais em Saúde com ênfase em Psicologia Social, Gênero e Política de Assistência Social, pesquisadora do Grupo de Pesquisa Martín-Baró: Psicologia Social, Política e Direitos Humanos e coordenadora da Associação Brasileira de Psicologia Social (ABRAPSO) de Juiz de Fora.

\section{COMO CITAR ESSE ARTIGO DE ACORDO COM AS NORMAS DA REVISTA}

MACHADO, Camila Borges. "Desigualdades de gênero na democracia brasileira". Revista Estudos Feministas, Florianópolis, v. 28, n. 3, e67478, 2020.

\section{CONTRIBUIÇÃO DE AUTORIA}

Não se aplica

\section{FINANCIAMENTO}

Não se aplica

\section{CONSENTIMENTO DE USO DE IMAGEM}

Não se aplica

APROVAÇÃO DE COMITÊ DE ÉTICA EM PESQUISA

Não se aplica

CONFLITO DE INTERESSES

Não se aplica

LICENÇA DE USO

Este artigo está licenciado sob a Licença Creative Commons CC-BY International. Com essa licença você pode compartilhar, adaptar, criar para qualquer fim, desde que atribua a autoria da obra.

\section{HISTÓRICO}

Recebida em 09/09/2019

Aceita em 08/12/2019 